\title{
Phenotypic plasticity of thermal tolerances in five oribatid mite species from sub-Antarctic Marion Island
}

\author{
Jacques A. Deere ${ }^{\mathrm{a}}$, Brent J. Sinclair ${ }^{\mathrm{a}, 1}$, David J. Marshall ${ }^{\mathrm{b}}$, Steven L. Chown ${ }^{\mathrm{a}, *}$ \\ ${ }^{a}$ Centre for Invasion Biology, Department of Botany and Zoology, Stellenbosch University, Private Bag X1, Matieland 7602, South Africa \\ ${ }^{\mathrm{b}}$ Department of Biology, Universiti Brunei Darussalam, Jalan Tungku Link, Gadong BE 1410, Brunei Darussalam
}

Received 20 December 2005; received in revised form 17 March 2006; accepted 27 March 2006

\begin{abstract}
The extent to which phenotypic plasticity might mediate short-term responses to environmental change is controversial. Nonetheless, theoretical work has made the prediction that plasticity should be common, especially in predictably variable environments by comparison with those that are either stable or unpredictable. Here we examine these predictions by comparing the phenotypic plasticity of thermal tolerances (supercooling point (SCP), lower lethal temperature (LLT), upper lethal temperature (ULT)), following acclimation at either $0,5,10$ or $15^{\circ} \mathrm{C}$, for seven days, of five, closely-related ameronothroid mite species. These species occupy marine and terrestrial habitats, which differ in their predictability, on sub-Antarctic Marion Island. All of the species showed some evidence of pre-freeze mortality (SCPs -9 to $-23^{\circ} \mathrm{C}$; LLTs -3 to $-15^{\circ} \mathrm{C}$ ), though methodological effects might have contributed to the difference between the SCPs and LLTs, and the species are therefore considered moderately chill tolerant. ULTs varied between $36{ }^{\circ} \mathrm{C}$ and $41{ }^{\circ} \mathrm{C}$. Acclimation effects on SCP and LLT were typically stronger in the marine than in the terrestrial species, in keeping with the prediction of strong acclimation responses in species from predictably variable environments, but weaker responses in species from unpredictable environments. The converse was found for ULT. These findings demonstrate that acclimation responses vary among traits in the same species. Moreover, they suggest that there is merit in assessing the predictability of changes in high and low environmental temperatures separately.
\end{abstract}

(C) 2006 Elsevier Ltd. All rights reserved.

Keywords: Phenotypic plasticity; Thermal tolerance; Supercooling point; Lower lethal temperature; Upper lethal temperature

\section{Introduction}

Given rapidly changing modern climates and their likely effects on organisms, amongst the most significant questions facing physiologists are the likely nature, extent and pace of species responses to their changing thermal and hygric environments (Hoffmann et al., 2003, 2005; Stillman, 2003; Helmuth et al., 2005; Somero, 2005). The extent and time-course of phenotypic plasticity are amongst the most challenging of these questions (Bale, 2002). For example, acclimation (or acclimatization in the field, both are forms of plasticity) might alter organismal perfor-

\footnotetext{
*Corresponding author. Tel.: + 2721808 2385; fax: + 27218082995 .

E-mail address: slchown@sun.ac.za (S.L. Chown).

${ }^{1}$ Current address: Department of Biological Sciences, University of Nevada, Las Vegas, NV 89154-4004, USA.
}

mance, but ultimately either have no influence on fitness or even reduce it as a consequence of complex trade-offs in resource allocation (Huey et al., 1999; Helmuth et al., 2005). Indeed, beneficial acclimation, defined by Leroi et al. (1994) as "... acclimation to a particular environment gives an organism a performance advantage in that environment over another organism that has not had the opportunity to acclimate to that particular environment", has proven controversial. Whilst acclimation (or acclimatization) has long been considered beneficial to organisms (Prosser, 1986; Spicer and Gaston, 1999), many recent studies have found no evidence for it (see Huey et al., 1999). In turn, these studies have been criticized from several perspectives. The majority of thermal acclimation tests of the beneficial acclimation hypothesis (BAH) are apparently neither direct nor complete because they assess the adaptive significance of developmental plasticity, rather than investigating what 
comparative physiologists regard as acclimation (Wilson and Franklin, 2002). In addition, many explicit tests of the BAH compare animals in optimal environments with those under stressful conditions (Woods and Harrison, 2002).

Such controversy regarding the form of phenotypic plasticity and the likely fitness consequences thereof suggests that much needs to be done to understand the circumstances under which phenotypic plasticity is promoted and when it is likely to be beneficial (Somero, 2005). Past work has suggested that acclimation (or acclimatization) is more likely in species from temperate than those from less variable tropical and polar environments (Spicer and Gaston, 1999; Ghalambor et al., 2006), and, more generally, less likely in stenothermal species occupying stable environments (Pörtner et al., 2000). Owing to marked differences in variability between terrestrial and aquatic (especially marine, non-intertidal) environments, it has also been suggested that the organisms inhabiting these environments are likely to show substantial differences in their responses to them (Chown et al., 2000; Klok et al., 2004).

Moreover, recent theoretical work has shown that if environmental cues are misleading, plasticity will not be favoured (Tufto, 2000; Berrigan and Scheiner, 2004). Arguably, environmental unpredictablility, rather than variability per se, is prone to make cues even more misleading (Levins, 1969; Kingsolver and Huey, 1998). Whilst unpredictable environments are by necessity variable, the time course of that variability might be predictable or unpredictable. This is most readily illustrated by an example. At coastal sites on Marion Island, and at Lambert's Bay on the west coast of South Africa, microclimate temperatures vary from day to day (as they do everywhere). At Lambert's Bay the variation is completely predictable. That is, very similar temperatures occur at the same time of day, every day for more than a week (Fig. 1A). By contrast, although temperatures also vary at Marion Island, it is not possible to predict, from day to day, what those temperatures will be at a given time (Fig. 1B). Thus, although both sites are variable, the predictability of that variation is high at one site and low at the other. It is in temporally varying, unpredictable circumstances where bias of the phenotype towards some global optimum would be most beneficial (Tufto, 2000). Thus, it might be expected that in predictably variable environments, species will be more likely to respond to changing environments via acclimation (i.e. show more pronounced phenotypic plasticity), than in either unpredictable or very stable environments. At least in the latter case, this seems to be true (Spicer and Gaston, 1999; Peck et al., 2004; Somero, 2005). However, investigations of the effects of environmental predictability on the extent of acclimation are less common (Kingsolver and Huey, 1998).

In this study we examine the above hypotheses by investigating the thermal tolerance responses to acclimation of five species of ameronothroid mites from subAntarctic Marion Island. In particular, we first determine
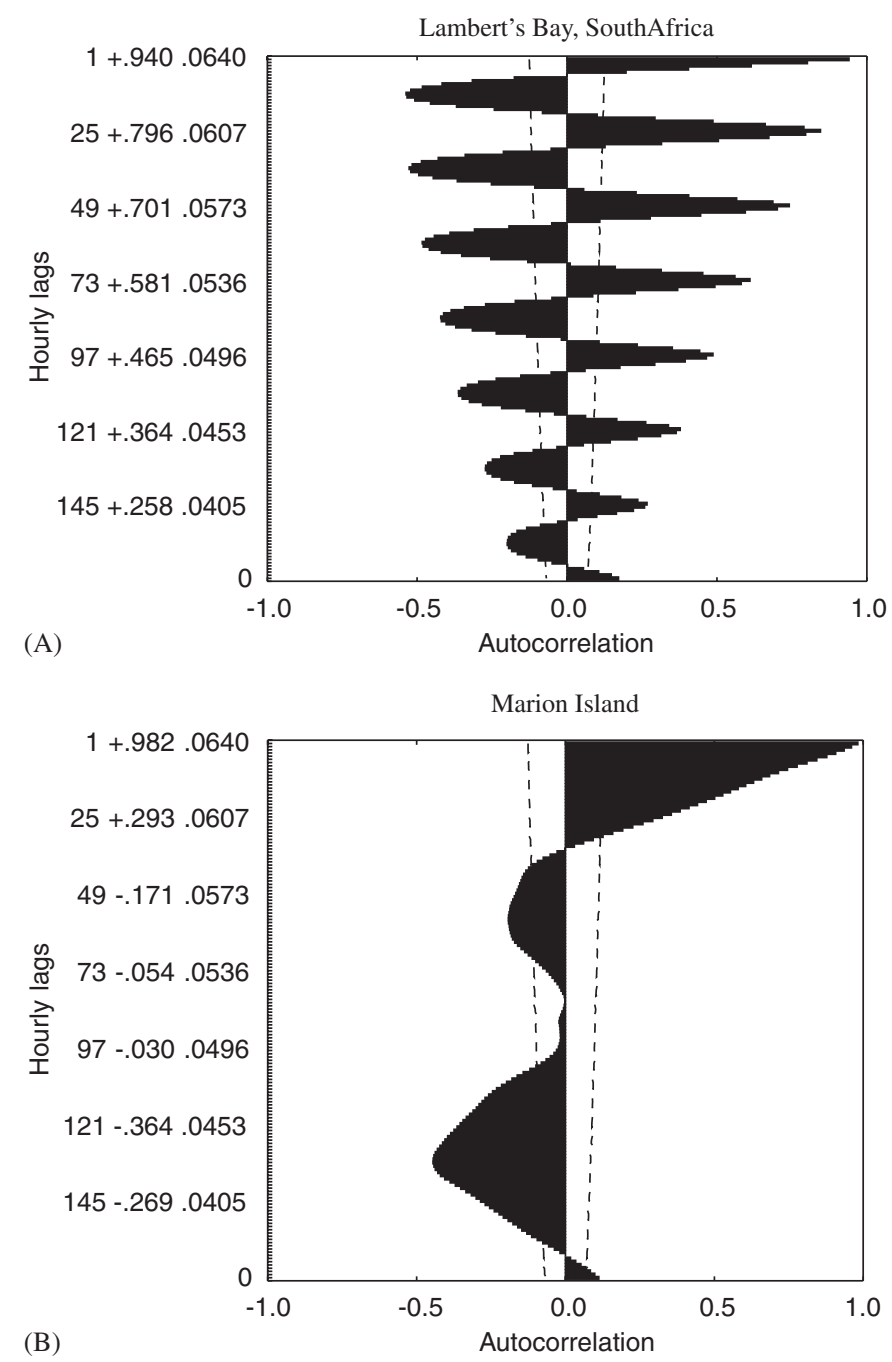

Fig. 1. Autocorrelation plots for hourly microclimate temperatures recorded using Thermochron iButtons (Dallas Semiconductors, Model DS1920) just below the soil surface during August 2002 at (A) Lambert's Bay, South Africa, and (B) a coastal site on sub-Antarctic Marion Island. The dashed lines on each figure represent the $95 \%$ confidence intervals, whilst the values reported to the right of the lags on the $y$-axis are the autocorrelation coefficients and their standard errors. These figures indicate that terrestrial microclimate temperatures are not predictable from day to day at Marion Island, but are perfectly predictable for nearly a week at Lambert's Bay.

whether the species' responses to acclimation were inconsistent with the predictions of three hypotheses: beneficial acclimation (as defined previously), deleterious acclimation (extreme acclimation temperatures have negative effects on the organisms - see Loeschcke and Hoffmann, 2002), and no acclimation (no changes in the traits of interest in response to acclimation). In the context of the resistance traits examined here, it is difficult to distinguish the beneficial acclimation hypothesis from the 'colder is better' (CIB) and 'warmer is better' (WIB) alternatives (see Huey and Berrigan, 1996). Therefore, we make no attempt to do so. Second, because the mite species occupy a range of habitats from wholly marine to terrestrial (Barendse et al., 
Table 1

Sea surface (SS) temperature $\left({ }^{\circ} \mathrm{C}\right)$ and microhabitat temperatures $\left({ }^{\circ} \mathrm{C}\right)$ of nine terrestrial sites $(0 \mathrm{~m}$ to $800 \mathrm{~m}$ a.s.l.) for two years at Marion Island

\begin{tabular}{|c|c|c|c|c|c|c|}
\hline Year & Mean & Abs Min & Abs Max & Mean Min & Mean Max & Range \\
\hline \multicolumn{7}{|l|}{ SS } \\
\hline 2002 & 5.4 & 3.7 & 8.5 & 4.9 & 6.2 & 4.8 \\
\hline 2003 & 5.4 & 3.7 & 8.0 & 4.7 & 6.0 & 4.3 \\
\hline \multicolumn{7}{|l|}{$0 \mathrm{~m}$} \\
\hline 2002 & 5.3 & 0.5 & 22.5 & 3.8 & 7.1 & 22.0 \\
\hline 2003 & 7.0 & 1.0 & 22.0 & 5.1 & 8.6 & 21.0 \\
\hline \multicolumn{7}{|l|}{$100 \mathrm{~m}$} \\
\hline 2002 & 5.2 & 0.0 & 16.0 & 3.1 & 7.7 & 16.0 \\
\hline 2003 & 5.7 & 0.5 & 17.5 & 3.7 & 8.1 & 17.0 \\
\hline \multicolumn{7}{|l|}{$200 \mathrm{~m}$} \\
\hline 2002 & 4.4 & -5.0 & 18.5 & 2.2 & 7.0 & 23.5 \\
\hline 2003 & 5.2 & -6.0 & 19.0 & 3.5 & 6.6 & 25.0 \\
\hline \multicolumn{7}{|l|}{$300 \mathrm{~m}$} \\
\hline 2002 & 4.1 & 0.0 & 15.0 & 2.4 & 6.1 & 15.0 \\
\hline 2003 & 4.2 & -1.0 & 15.5 & 2.4 & 6.3 & 16.5 \\
\hline \multicolumn{7}{|l|}{$400 \mathrm{~m}$} \\
\hline 2002 & 2.8 & -1.0 & 13.0 & 1.8 & 5.7 & 14.0 \\
\hline 2003 & 3.1 & -0.5 & 12.5 & 1.9 & 6.0 & 13.0 \\
\hline \multicolumn{7}{|l|}{$500 \mathrm{~m}$} \\
\hline 2002 & 3.5 & 0.0 & 24.0 & 1.8 & 6.1 & 24.0 \\
\hline 2003 & 3.6 & -6.5 & 30.0 & 1.6 & 6.4 & 36.5 \\
\hline \multicolumn{7}{|l|}{$600 \mathrm{~m}$} \\
\hline 2002 & 2.5 & 0.0 & 11.5 & 1.8 & 4.1 & 11.5 \\
\hline 2003 & 2.7 & -0.5 & 13.0 & 1.9 & 5.0 & 13.5 \\
\hline \multicolumn{7}{|l|}{$700 \mathrm{~m}$} \\
\hline 2002 & 2.5 & -7.0 & 17.5 & 0.5 & 4.8 & 24.5 \\
\hline 2003 & 3.0 & -1.5 & 22.5 & 1.4 & 5.2 & 24.0 \\
\hline \multicolumn{7}{|l|}{$800 \mathrm{~m}$} \\
\hline 2002 & 1.5 & -12.0 & 23.0 & -0.3 & 3.6 & 35.0 \\
\hline 2003 & 1.8 & -4.5 & 19.5 & 0.3 & 3.6 & 24.0 \\
\hline
\end{tabular}

Mean, mean minimum (Mean min) and mean maximum (Mean max), absolute minimum (Abs min) and absolute maximum (Abs max) temperatures, and temperature range are given for each site for each year. Terrestrial data were collected using Thermochron iButton loggers (Dallas Semiconductors, Model DS1920) placed just below the soil surface, whilst sea temperature data were collected using a mercury in glass thermometer by staff of the South African Weather Services as part of the routine meteorological observations.

2002), we test the prediction that the more marine species should show a greater response to acclimation than their terrestrial counterparts, because the marine species experience a predictable thermal environment with small seasonal variation, whilst the terrestrial species experience a more variable, though unpredictable environment (Table 1).

\section{Materials and methods}

\subsection{Study site and animals}

Specimens were collected from April 2002 to April 2003 on the east coast of sub-Antarctic Marion Island (46 $54^{\prime} \mathrm{S}$, $\left.37^{\circ} 45^{\prime}\right)$. The island has a low mean annual air temperature (c. $\left.5.7^{\circ} \mathrm{C}\right)$, high humidity $(83 \%)$, an annual precipitation of approximately $1900 \mathrm{~mm}$ (which is distributed evenly throughout the year), a high degree of cloudiness, and strong, predominantly westerly winds (Smith, 2002).
Five species were investigated: Halozetes marinus (mean \pm S.E. mass: $0.095 \pm 0.002 \mathrm{mg}$ ), Halozetes marionensis (mass: $0.067 \pm 0.002 \mathrm{mg}$ ), Halozetes belgicae (mass: $0.033 \pm 0.001 \mathrm{mg}$ ), Halozetes fulvus (mass: $0.031 \pm$ $0.001 \mathrm{mg})$ and Podacarus auberti $(0.195 \pm 0.006 \mathrm{mg})$. All five species are ecologically separated in the marine and terrestrial environments. $H$. marinus Engelbrecht and $H$. marionensis Engelbrecht are found in the marine littoral zone occurring, respectively, in the red seaweeds in the lower shore and in the black lichen Verrucaria sp. which dominates the upper shore (Mercer et al., 2000). H. marinus also occurs in thick mats of filamentous algae on sheltered shores (Mercer et al., 2000). H. belgicae Michael occurs in Turgidosculum complicatulum and Caloplaca sp. in the supra-littoral zone. H. fulvus and Podacarus auberti are predominantly found in terrestrial environments on moss (e.g. Sanionia uncinata), and on Poa cookii, respectively (Mercer et al., 2000; Barendse et al., 2002). 
Specimens were collected at Transvaal Cove, Macaroni Bay, Archway, Duikers Point River, and the area immediately around the Entomology laboratory at the scientific station. All of the sites are situated on the east coast of the island and the distance from the northern most site (Duikers Point) to the southern most site (Archway) is approximately $4 \mathrm{~km}$.

\subsection{Acclimation}

Plant samples were collected from the field, placed into plastic bags and returned to the laboratory within two hours to extract animals. H. marionensis was the only species to be collected directly from the rock-substrate on which it occurs. Specimens of $H$. marionensis were removed from the rock and placed, with a sample of the vegetation on which they feed, into vials containing moistened plasterof-Paris substrate and returned to the laboratory within two hours. Specimens in the laboratory were kept in vials with a moistened plaster-of-Paris substrate, and housed in preset incubators at one of four acclimation temperatures $\left(0,5,10,15^{\circ} \mathrm{C}, \pm 1{ }^{\circ} \mathrm{C}\right.$ in each case) for seven days for a set of experiments. Animals were fed on the plant material from which they were collected. Day length was set at 14:10 light-dark cycles (L:D) for the 10 and $15^{\circ} \mathrm{C}$ incubators (summer conditions) and at 9:15 L:D for the 0 and $5^{\circ} \mathrm{C}$ incubators (winter conditions).

\subsection{Supercooling point (crystallization temperature)}

Supercooling point (SCP) experiments were carried out with a sample of at least 20 individuals for each acclimation temperature for each species. Animals were attached to the end of a thermocouple (Type T 40-SWG) with small amounts of thermally inert silicon grease and then placed in the end of a pipette tip. The pipette tip was placed into a sealed test tube and submerged in a Grant LTC 12 water bath (Grant Instruments, Cambridge, UK). The thermocouples were attached to a Campbell CR-10 (Campbell Scientific Inc., UK) or Pico (Pico Technology LTD, UK) data logger, and measurements taken every second.

Many supercooling point experiments have used a cooling rate of $1{ }^{\circ} \mathrm{C} \mathrm{min}^{-1}$ (Chown and Nicolson, 2004), although a rate of closer to $0.01{ }^{\circ} \mathrm{C} \mathrm{min}^{-1}$ is more common in the field (Sinclair, 2001). For these experiments a compromise cooling rate of $0.1^{\circ} \mathrm{Cmin}^{-1}$ was used. Animals were initially held at $0^{\circ} \mathrm{C}$ for $15 \mathrm{~min}$ for those animals acclimated at $0{ }^{\circ} \mathrm{C}$, and at $5{ }^{\circ} \mathrm{C}$ for those acclimated at 5,10 and $15^{\circ} \mathrm{C}$, after which the animals were cooled to $-30^{\circ} \mathrm{C}$. The lowest temperature reached before the onset of an exotherm (latent heat of crystallization) was taken as the SCP for that individual (Lee, 1991). Immediately following completion of its exotherm, an individual was removed from the water bath and then given an opportunity to recover at its original acclimation temperature. Survival was checked at 24 and $48 \mathrm{~h}$. Treatment effects within species were investigated using a generalized linear model assuming a normal distribution and using an identity link function (Quinn and Keough, 2002).

\subsection{Lower and upper lethal temperatures}

In isolation, supercooling points provide only superficial insight into the cold hardiness strategy of a species (Baust and Rojas, 1985; Bale, 1993). They do not allow detection of pre-freeze mortality, nor of survival below the freezing point. Moreover, even in species where death at the freezing point is expected, it is becoming increasingly clear that SCPs alone are problematic when it comes to interpretation of cold hardiness and its adaptive value (Worland, 2005; Worland et al., 2006). Therefore, lower lethal temperatures were determined in addition to SCPs. Upper thermal limits were also determined. For lower (LLT) and upper (ULT) lethal temperatures, five replicates of 10 animals were used for each temperature in all species except for $H$. fulvus for which five animals were used in each replicate. For the LLT experiments a wet and a dry treatment was used to investigate likely effects of inoculation. For the wet treatment, animals were placed onto moist filter paper during the course of the experiment, whilst in the dry treatment the animals were placed above dry silica gel. The animals were not placed directly on the silica gel to avoid possible cuticular damage. Animals in the upper lethal limits experiments were placed on moistened filter paper only as the intention was not to measure desiccation resistance. In each case the treatment was effected by placing each batch of animals into a $1.5 \mathrm{ml}$ eppendorf vial.

The vials were then submerged in a water bath at a given temperature for one hour. They were subsequently removed and transferred to a recovery vial at the original acclimation temperature. For field-fresh animals recovery temperatures were set to $5^{\circ} \mathrm{C}$. After 24 and $48 \mathrm{~h}$ animals were scored for survival. Survival was considered as coordinated movement, while twitching or uncoordinated movement indicated a moribund state, and no movement indicated mortality. The temperature was then lowered (in the case of the LLT experiments) or increased (in the case of ULT experiments) by $1{ }^{\circ} \mathrm{C}$ increments and the assessment repeated with new animals. Experiments were continued until the proportion of survivors varied between 0 and 1 . For the LLT and ULT mortality data a logistic regression was used to calculate LT50 values (the point where $50 \%$ of the population survived). This procedure was only applied where the logistic regression provided a significant fit to the data based on the Wald statistic (Quinn and Keough, 2002). The treatment effects within each species were investigated using a generalized linear model assuming a normal distribution and using an identity link function (Quinn and Keough, 2002), and comparisons made using $95 \%$ confidence intervals.

To examine the prediction that the species from the more predictable, though less variable marine environment show greater phenotypic plasticity relative to the species from the 
more variable, though less predictable terrestrial environment, the largest difference in each of the traits across the four acclimation temperatures for each of the species was compared. This was done by calculation of the largest difference between any two acclimation temperatures, except where acclimation was thought to be somehow deleterious (Klok and Chown, 2003).

\section{Results}

No individuals survived freezing, and the SCPs were usually lower than the dry LLT50s, suggesting some prefreeze mortality (Table 2). In H. marionensis the SCP and the dry LLT50 values after acclimation at $10^{\circ} \mathrm{C}$ were similar, making this species and treatment the only exception. In the more marine species (H. marinus and $H$. marionensis) declining acclimation temperature resulted in a significant decline in SCP, whereas no significant effects were found in the more terrestrial species (Table 2).

Acclimation typically had a significant effect on the dry LLT50s, resulting in a decline in LLT50 with a lower acclimation temperature (Table 2). In Podacarus auberti this took the form of a threshold effect at $15^{\circ} \mathrm{C}$, whereas no significant effect of acclimation was found in $H$. fulvus from a similar habitat. Once again, the acclimation effects were more pronounced in the marine than in the terrestrial species. By contrast, acclimation had a smaller and less consistent effect on the wet LLT50 treatment in all of the species, although the differences between acclimation temperatures were typically significant (Table 2).

In the case of ULT50, incubator failure resulted in a loss of some data for $H$. marinus and $H$. marionensis. Nonetheless, it was clear that lower acclimation temperatures typically resulted in a decline in ULT50, and the extent of this change was similar to that found for the LLT50 dry treatments in the terrestrial species, but not in the marine ones (Table 2). Indeed, even when comparisons were restricted to the $0-10{ }^{\circ} \mathrm{C}$ acclimation temperatures, it was clear that the terrestrial species tended to have a more pronounced response in ULT50 than the marine ones, which is the converse of the situation found for SCP and the dry LLT50s.

Table 2

Mean $\left({ }^{\circ} \mathrm{C}\right) \pm$ standard error of supercooling point (SCP), lower lethal temperature (LLT50) and upper lethal temperature (ULT50) for each of five mite species acclimated to four temperatures $\left({ }^{\circ} \mathrm{C}\right)$

\begin{tabular}{|c|c|c|c|c|c|}
\hline & H. marinus & H. marionensis & H. belgicae & H. fulvus & Podacarus auberti \\
\hline \multicolumn{6}{|l|}{ SCP } \\
\hline $0^{\circ} \mathrm{C}$ & $-23.1 \pm .5^{\mathrm{a}}$ & $-20.3 \pm 0.9^{\mathrm{a}}$ & $-18.1 \pm 1.4^{\mathrm{a}}$ & $-16.3 \pm 1.1$ & $-17.0 \pm 1.3$ \\
\hline $5^{\circ} \mathrm{C}$ & $-21.0 \pm 0.9^{\mathrm{a}}$ & $-12.8 \pm 1.3^{\mathrm{b}}$ & $-17.8 \pm 1.1^{\mathrm{a}}$ & $-18.5 \pm 1.2$ & $-13.2 \pm 1.5$ \\
\hline $10^{\circ} \mathrm{C}$ & $-22.9 \pm 0.5^{\mathrm{a}}$ & $-9.0 \pm 1.4^{\mathrm{b}, \mathrm{c}}$ & $-16.9 \pm 13^{\mathrm{a}}$ & $-15.8 \pm 0.6$ & $-14.9 \pm 1.4$ \\
\hline $15^{\circ} \mathrm{C}$ & $-14.4 \pm 1.2^{\mathrm{b}}$ & $-5.0 \pm 0.7^{\mathrm{c}}$ & $-19.3 \pm 1.0^{\mathrm{a}}$ & $-15.9 \pm 1.2$ & $-14.0 \pm 1.2$ \\
\hline & $\chi_{(3)}^{2}=73.6^{* * *}$ & $\chi_{(3)}^{2}=98.5^{* * *}$ & $\chi_{(3)}^{2}=1.8^{\mathrm{NS}}$ & $\chi_{(3)}^{2}=4.6^{\mathrm{NS}}$ & $\chi_{(3)}^{2}=4.2^{\mathrm{NS}}$ \\
\hline Difference & 8.7 & 15.3 & 2.4 & 2.7 & 3.8 \\
\hline \multicolumn{6}{|l|}{ LLT (wet) } \\
\hline $0{ }^{\circ} \mathrm{C}$ & $-5.9 \pm 0.09^{\mathrm{ab}}$ & $-5.4 \pm 0.13^{\mathrm{a}}$ & $-4.7 \pm 0.15^{\mathrm{a}}$ & $-6.9 \pm 0.08^{\mathrm{a}}$ & $-5.1 \pm 0.14^{\mathrm{a}}$ \\
\hline $5^{\circ} \mathrm{C}$ & $-6.3 \pm 0.15^{\mathrm{a}}$ & $-4.8 \pm 0.15^{\mathrm{a}, \mathrm{b}}$ & $-4.6 \pm 0.2^{\mathrm{ab}}$ & $-7.8 \pm 0.09^{\mathrm{ab}}$ & $-4.8 \pm 0.19^{\mathrm{ab}}$ \\
\hline $10^{\circ} \mathrm{C}$ & $-7.0 \pm 0.26^{\mathrm{ab}}$ & $-4.2 \pm 0.24^{\mathrm{b}}$ & $-4.7 \pm 0.18^{\mathrm{a}}$ & $-8.5 \pm 0.06^{\mathrm{b}}$ & $-4.4 \pm 0.28^{b}$ \\
\hline $15^{\circ} \mathrm{C}$ & $-4.4 \pm 0.16^{\mathrm{b}}$ & - & $-3.7 \pm 0.1^{\mathrm{b}}$ & $-6.8 \pm 0.09^{\mathrm{a}}$ & $-4.4 \pm 0.3^{\mathrm{ab}}$ \\
\hline & $\chi_{(3)}^{2}=28.5^{* * *}$ & $\chi_{(2)}^{2}=10.9^{*}$ & $\chi^{2}(3)=34.0^{* * *}$ & $\chi_{(3)}^{2}=19.3^{* * *}$ & $\chi_{(3)}^{2}=24.8^{* * *}$ \\
\hline Difference & 2.62 & 1.26 & 1.04 & 1.66 & 0.72 \\
\hline \multicolumn{6}{|l|}{ LLT (dry) } \\
\hline $0^{\circ} \mathrm{C}$ & $-10.4 \pm 0.05^{\mathrm{a}, \mathrm{b}}$ & $-14.0 \pm 0.05^{\mathrm{a}}$ & $-10.3 \pm 0.04^{\mathrm{a}}$ & $-11.6 \pm 0.06$ & $-5.8 \pm 0.04^{\mathrm{a}}$ \\
\hline $5^{\circ} \mathrm{C}$ & $-11.4 \pm 0.04^{\mathrm{a}}$ & $-10.4 \pm 0.04^{\mathrm{b}}$ & $-5.6 \pm 0.05^{\mathrm{b}}$ & $-10.5 \pm 0.05$ & $-5.2 \pm 0.05^{\mathrm{a}}$ \\
\hline $10^{\circ} \mathrm{C}$ & $-14.5 \pm 0.06^{\mathrm{c}}$ & $-9.6 \pm 0.04^{\mathrm{b}}$ & $-7.0 \pm 0.05^{\mathrm{b}}$ & $-11.5 \pm 0.05$ & $-5.3 \pm 0.05^{\mathrm{a}}$ \\
\hline $15^{\circ} \mathrm{C}$ & $-8.8 \pm 0.07^{\mathrm{b}}$ & - & $-8.8 \pm 0.05^{\mathrm{a}, \mathrm{b}}$ & $-11.5 \pm 0.07$ & $-2.7 \pm 0.07^{\mathrm{b}}$ \\
\hline & $\chi_{(3)}^{2}=85.6^{* * *}$ & $\chi_{(2)}^{2}=64.1^{* * *}$ & $\chi_{(3)}^{2}=52.6^{* * *}$ & $\chi_{(3)}^{2}=6.5^{\mathrm{NS}}$ & $\chi_{(3)}^{2}=93.5^{* *}$ \\
\hline Difference & 5.63 & 4.35 & 4.73 & 1.08 & 3.09 \\
\hline \multicolumn{6}{|l|}{ ULT } \\
\hline $0^{\circ} \mathrm{C}$ & $36.1 \pm 0.41^{\mathrm{a}}$ & $37.2 \pm 0.16$ & $36.5 \pm 0.21^{\mathrm{a}}$ & $37.7 \pm 1.08^{\mathrm{a}, \mathrm{b}}$ & $36.3 \pm 0.08^{\mathrm{a}}$ \\
\hline $5^{\circ} \mathrm{C}$ & $37.1 \pm 0.76^{\mathrm{b}}$ & $37.4 \pm 0.14$ & $38.9 \pm 0.18^{\mathrm{b}}$ & $37.3 \pm 0.43^{\mathrm{b}}$ & $38.6 \pm 0.50^{\mathrm{b}}$ \\
\hline $10^{\circ} \mathrm{C}$ & $37.9 \pm 0.69^{c}$ & - & $40.7 \pm 0.16^{\mathrm{c}}$ & $39.0 \pm 0.34^{\mathrm{a}}$ & $39.5 \pm 0.32^{\mathrm{b}}$ \\
\hline $15^{\circ} \mathrm{C}$ & - & - & $40.1 \pm 0.2^{\mathrm{c}}$ & $39.9 \pm 0.28^{\mathrm{a}}$ & $39.5 \pm 0.3^{\mathrm{b}}$ \\
\hline & $\chi_{(2)}^{2}=254.6^{* * *}$ & $\chi_{(1)}^{2}=0.4^{\mathrm{NS}}$ & $\chi_{(3)}^{2}=410.9^{* * *}$ & $\chi_{(3)}^{2}=114.6^{* * *}$ & $\chi_{(3)}^{2}=269.3^{* * *}$ \\
\hline Difference & 1.79 & 0.21 & 4.16 & 2.66 & 3.26 \\
\hline
\end{tabular}

Superscript letters indicate significant differences between the four acclimation temperatures $\left({ }^{\circ} \mathrm{C}\right)$ for each species based on the $95 \%$ confidence intervals from a generalized linear model assuming a normal distribution with an identity link function (NS = not significant; ${ }^{*} p<0.05 ; * * p<0.001 ;{ }^{* * *} p<0.0001$ ). The largest difference in each of the traits across the four acclimation temperatures for each of the species was compared by calculation of the largest difference between any two acclimation temperatures. 


\section{Discussion}

All of the mite species that were investigated here are freeze-intolerant, a strategy that is almost universal in mites and springtails (Cannon and Block, 1988; Sinclair et al., 2003). Moreover, the supercooling points documented for the species here are reasonably similar to those of related species, such as Halozetes littoralis from South Georgia which typically freezes at $-16.6^{\circ} \mathrm{C}$ (Pugh, 1994), but higher than those of Alaskozetes antarcticus from Signy Island which has a supercooling point of $\leqslant-24^{\circ} \mathrm{C}$ (Young and Block, 1980; Block and Convey, 1995). However, in all species and following all of the acclimations (with the exception of $\mathrm{H}$. marionensis following acclimation to $10^{\circ} \mathrm{C}$ ) the supercooling point was lower than, and thus not equivalent to, the lower lethal temperature. This suggests that some pre-freeze mortality took place in all of the species investigated. Pre-freeze mortality has been observed in several species of mites (Hart et al., 2002; Hatherly et al., 2004) and insects (Baust and Rojas, 1985; Bale, 1987, 1993; Koštál et al., 2004), and its occurrence here is therefore not surprising. However, differences in the experimental protocol used to calculate SCP and the LLT50s may have made some contribution to the observed pre-freeze mortality. Unfortunately, this could not be independently verified.

Therefore, it seems safest to propose that there is at least some pre-freeze mortality in the species examined here, which would make these species moderately chill-tolerant, rather than freeze-avoiding (see Bale, 1996). This level of chill tolerance is similar to the cold hardiness strategies found in several other arthropod species on Marion Island (Klok and Chown, 2001; Van der Merwe et al., 1997; Slabber and Chown, 2004). Moreover, it is in keeping with the generally high subzero microclimate temperatures which the mite species are likely to encounter (Table 1). Nonetheless, the extent of chill tolerance in the mite species investigated here is not as pronounced as that found in the highly chill tolerant Antarctic mite A. antarcticus (Bale, 1993).

That the LLTs differed in the wet and dry treatments is unsurprising. The presence of free water is known to have a significant effect on the likelihood of heterogeneous nucleation owing to the fact that ice crystals can serve as an inoculum for further ice formation, and indeed may sometimes be required to ensure freezing at relatively high subzero temperatures (reviews in Zachariassen, 1985; Lee and Denlinger, 1991; Ramløv, 2000). Thus, the expectation is that acclimation effects on SCPs would be masked to a large extent by the effects of nucleation from ice-crystals surrounding the mites in the wet treatment, and this is indeed what we found.

The ULTs of all five mite species were much higher than those of several other arthropod species on Marion Island (Van der Merwe et al., 1997; Slabber and Chown, 2004), but they fell within the same range as the $\mathrm{CT}_{\max }$ values for many of the island's arthropods $\left(35.5-39.7^{\circ} \mathrm{C}\right)$ (Klok and
Chown, 1997, 1998, 2001, 2003). In addition, the ULTs are high enough to ensure tolerance of the absolute maximum temperatures likely to be experienced by these species in their microhabitats, including the uncommonly high microclimate temperatures that may occasionally occur (Table 1).

In response to the acclimation treatments the marine species, H. marinus and $H$. marionensis, showed pronounced changes in SCP and in dry LLT50 values. The direction of these values was in keeping with what might be expected from the beneficial acclimation hypothesis (Leroi et al., 1994). However, the nature of the trials did not allow us to distinguish this hypothesis from the 'CIB' and 'WIB' alternatives (Huey and Berrigan, 1996), and this is likely to be a problem in the assessment of most resistance traits. By contrast, either no acclimation-induced response (SCP), or a reduced response to acclimation (wet LLT50) was found in $H$. belgicae, $H$. fulvus and Podacarus auberti, suggesting that acclimation is of less importance in these species (i.e. the hypothesis of no acclimation is at least partially supported). Thus, the beneficial acclimation hypothesis (including CIB and WIB) seems to hold for the marine species, and the no acclimation hypothesis is partially supported for the terrestrial species. In consequence, the prediction that acclimation effects should be more pronounced in the moderately variable, but predictable marine environment, by comparison with the largely unpredictable, but substantially more variable terrestrial environment can also not be rejected. This outcome is in keeping with theoretical predictions of the conditions under which plasticity is most likely to develop (Kingsolver and Huey, 1998; Tufto, 2000; Berrigan and Scheiner, 2004).

However, the converse response to acclimation was found for ULT50, with the marine species showing a marginal change in ULT50, and the terrestrial species (excluding $H$. belgicae) a much larger one, although all significant changes were in a direction one might predict from the beneficial acclimation hypothesis. Decoupled responses to high and low temperatures are common in arthropods (and especially tracheated arthropods such as these mites) (Chown, 2001; Chown and Nicolson, 2004; Hoffmann et al., 2005), and are therefore unsurprising here. In addition, the very different responses of the three traits (SCP, LLT50 and ULT) to acclimation, and the comparative lack of plasticity in locomotor performance of the same mite species (Deere and Chown, unpublished data), support previous findings that acclimation responses are likely to vary considerably among traits (Woods and Harrison, 2001, 2002). Differences in trait responses to acclimation also suggest that maximum and minimum temperatures might show different levels of unpredictability. To date, variation in extreme temperatures, rather than means, has enjoyed little attention from this perspective (for additional discussion see Gaines and Denny, 1993; Kingsolver and Huey, 1998; Helmuth et al., 2005). 


\section{Acknowledgements}

John Terblanche, Emilie Gray and two anonymous referees are thanked for comments on the manuscript. The South African Weather Services provided sea surface temperature data. This study was partially supported by the USAID Capacity Building Programme for Climate Change Research and the South African Department of Environmental Affairs and Tourism.

\section{References}

Bale, J.S., 1987. Insect cold hardiness: freezing and supercooling-an ecophysiological perspective. Journal of Insect Physiology 33, 899-908.

Bale, J.S., 1993. Classes of insect cold hardiness. Functional Ecology 7, $751-753$.

Bale, J.S., 1996. Insect cold tolerance: a matter of life and death. European Journal of Entomology 93, 369-382.

Bale, J.S., 2002. Insects and low temperatures: from molecular biology to distributions and abundance. Philosophical Transactions of the Royal Society of London B 357, 849-862.

Barendse, J., Mercer, R.D., Marshall, D.J., Chown, S.L., 2002. Habitat specificity of mites on sub-Antarctic Marion Island. Environmental Entomology 31, 612-625.

Baust, J.G., Rojas, R.R., 1985. Insect cold hardiness: facts and fancy. Journal of Insect Physiology 31, 755-759.

Berrigan, D., Scheiner, S.M., 2004. Modeling the evolution of phenotypic plasticity. In: DeWitt, T.J., Scheiner, S.M. (Eds.), Phenotypic Plasticity: Functional and Conceptual Approaches. Oxford University Press, Oxford, pp. 82-97.

Block, W., Convey, P., 1995. The biology, life cycle and ecophysiology of the Antarctic mite Alaskozetes antarcticus. Journal of the Zoological Society of London 236, 431-449.

Cannon, R.J.C., Block, W., 1988. Cold tolerance of microarthropods. Biological Reviews 63, 23-77.

Chown, S.L., 2001. Physiological variation in insects: hierarchical levels and implications. Journal of Insect Physiology 47, 649-660.

Chown, S.L., Nicolson, S.W., 2004. Insect Physiological Ecology. Mechanisms and Patterns. Oxford University Press, Oxford.

Chown, S.L., Gaston, K.J., Gremmen, N.J.M., 2000. Including the Antarctic: insights for ecologists everywhere. In: Davison, W., Howard-Williams, C., Broady, P. (Eds.), Antarctic Ecosystems: Models for Wider Ecological Understanding. New Zealand Natural Sciences, Christchurch, pp. 1-15.

Gaines, S.D., Denny, M.W., 1993. The largest, smallest, highest, lowest, longest and shortest: extremes in ecology. Ecology 74, $1677-1692$

Ghalambor, C.K., Huey, R.B., Martin, P.R., Tewksbury, J.J., Wang, G., 2006. Are mountain passes higher in the tropics? Janzen's hypothesis revisited. Integrative and Comparative Biology 46, 5-17.

Hart, A.J., Bale, J.S., Tullett, A.G., Worland, M.R., Walters, K.F.A., 2002. Effects of temperature on the establishment potential of the predatory mite Amblyseius californicus McGregor (Acari : Phytoseiidae) in the U.K. Journal of Insect Physiology 48, 593-599.

Hatherly, I.S., Bale, J.S., Walters, K.F.A., Worland, M.R., 2004. Thermal biology of Typhlodromips montdorensis: implications for its introduction as a glasshouse biological control agent in the U.K. Entomologia Experimentalis et Applicata 111, 97-109.

Helmuth, B., Kingsolver, J.G., Carrington, E., 2005. Biophysics, physiological ecology, and climate change: does mechanism matter? Annual Review of Physiology 67, 177-201.

Hoffmann, A.A., Hallas, R.J., Dean, J.A., Schiffer, M., 2003. Low potential for climatic stress adaptation in a rainforest Drosophila species. Science 301, 100-102.
Hoffmann, A.A., Shirriffs, J., Scott, M., 2005. Relative importance of plastic $v s$ genetic factors in adaptive differentiation: geographical variation for stress resistance in Drosophila melanogaster from eastern Australia. Functional Ecology 19, 222-227.

Huey, R.B., Berrigan, D., 1996. Testing evolutionary hypotheses of acclimation. In: Johnston, I.A., Bennett, A.F. (Eds.), Animals and Temperature. Phenotypic and Evolutionary Adaptation. Cambridge University Press, Cambridge, pp. 205-237.

Huey, R.B., Berrigan, D., Gilchrist, G.W., Herron, J.C., 1999. Testing the adaptive significance of acclimation: a strong inference approach. American Zoologist 39, 323-336.

Kingsolver, J.G., Huey, R.B., 1998. Evolutionary analyses of morphological and physiological plasticity in thermally variable environments. American Zoologist 38, 545-560.

Klok, C.J., Chown, S.L., 1997. Critical thermal limits, temperature tolerance and water balance of a sub-Antarctic caterpillar, Pringleophaga marioni Viette (Lepidoptera: Tineidae). Journal of Insect Physiology 43, 685-694.

Klok, C.J., Chown, S.L., 1998. Interactions between desiccation resistance, host-plant contact and thermal biology of a leaf-dwelling sub-Antarctic caterpillar, Embryonopsis halticella (Lepidoptera: Yponomeutidae). Journal of Insect Physiology 44, 615-628.

Klok, C.J., Chown, S.L., 2001. Critical thermal limits, temperature tolerance and water balance of a sub-Antarctic kelp fly, Paractora dreuxi (Diptera: Helcomyzidae). Journal of Insect Physiology 47, 95-109.

Klok, C.J., Chown, S.L., 2003. Resistance to temperature extremes in subAntarctic weevils: interspecific variation, population differentiation and acclimation. Biological Journal of the Linnean Society 78, 401-414.

Klok, C.J., Sinclair, B.J., Chown, S.L., 2004. Upper thermal tolerance and oxygen limitation in terrestrial arthropods. Journal of Experimental Biology 207, 2361-2370.

Koštál, V., Vambera, J., Bastl, J., 2004. On the nature of pre-freeze mortality in insects: water balance, ion homeostasis and energy charge in the adults of Pyrrhocoris apterus. Journal of Experimental Biology 207, 1509-1521.

Lee, R.E., 1991. Principles of insect low temperature tolerance. In: Lee, R.E., Denlinger, D.L. (Eds.), Insects at Low Temperature. Chapman \& Hall, New York, pp. 17-46.

Lee, R.E., Denlinger, D.L., 1991. Insects at Low Temperature. Chapman \& Hall, New York.

Leroi, A.M., Bennett, A.F., Lenski, R.E., 1994. Temperature acclimation and competitive fitness: an experimental test of the beneficial acclimation assumption. Proceedings of the National Academy of Sciences of the USA 91, 1917-1921.

Levins, R., 1969. Thermal aclimation and heat resistance in Drosophila species. American Naturalist 103, 483-499.

Loeschcke, V., Hoffmann, A.A., 2002. The detrimental acclimation hypothesis. Trends in Ecology and Evolution 17, 407-408.

Mercer, R.D., Chown, S.L., Marshall, D.J., 2000. Mite and insect zonation on a Marion Island rocky shore: a quantitative approach. Polar Biology 23, 775-784.

Peck, L.S., Webb, K.E., Bailey, D.M., 2004. Extreme sensitivity of biological function to temperature in Antarctic marine species. Functional Ecology 19, 625-630.

Pörtner, H.O., Bock, C., Reipschläger, A., 2000. Modulation of the cost of pHi regulation during metabolic depression: a ${ }^{31} \mathrm{P}-\mathrm{NMR}$ study in invertebrate (Sipunculus nudus) isolated muscle. Journal of Experimental Biology 203, 2417-2428.

Prosser, C.L., 1986. Adaptational Biology. Molecules to Organisms. Wiley, New York.

Pugh, P.J.A., 1994. Supercooling points and water content in Acari. Acta Oecologica 15, 71-77.

Quinn, G.P., Keough, M.J., 2002. Experimental Design and Data Analysis for Ecologists. Cambridge University Press, Cambridge.

Ramløv, H., 2000. Aspects of natural cold tolerance in ectothermic animals. Human Reproduction 15, 26-46. 
Sinclair, B.J., 2001. Field ecology of freeze tolerance: interannual variation in cooling rates, freeze-thaw and thermal stress in the microhabitat of the alpine cockroach Celatoblatta quinquemaculata. Oikos 93, 286-293.

Sinclair, B.J., Addo-Bediako, A., Chown, S.L, 2003. Climate variability and the evolution of insect freeze tolerance. Biological Reviews 78, 181-195.

Slabber, S., Chown, S.L., 2004. Thermal tolerance and cold hardiness strategy of the sub-Antarctic psocid Antarctopsocus jeanneli Badonnel. Polar Biology 28, 56-61.

Smith, V.R., 2002. Climate change in the sub-Antarctic: an illustration from Marion Island. Climatic Change 52, 345-357.

Somero, G.N., 2005. Linking biogeography to physiology: evolutionary and acclimatory adjustments of thermal limits. Frontiers in Zoology 2,1 .

Spicer, J.I., Gaston, K.J., 1999. Physiological Diversity and its Ecological Implications. Blackwell Science, Oxford.

Stillman, J.H., 2003. Acclimation capacity underlies susceptibility to climate change. Science 301, 65.

Tufto, J., 2000. The evolution of plasticity and nonplastic spatial and temporal adaptations in the presence of imperfect environmental cues. American Naturalist 156, 121-130.
Van der Merwe, M., Chown, S.L., Smith, V.R., 1997. Thermal tolerance limits of six weevil species (Coleoptera, Curculionidae) from subAntarctic Marion Island. Polar Biology 18, 331-336.

Wilson, R.S., Franklin, C.E., 2002. Testing the beneficial acclimation hypothesis. Trends in Ecology and Evolution 17, 66-70.

Woods, H.A., Harrison, J.F., 2001. The beneficial acclimation hypothesis versus acclimation of specific traits: physiological change in water stressed Manduca sexta. Physiological and Biochemical Zoology 74, $32-44$.

Woods, H.A., Harrison, J.F., 2002. Interpreting rejections of the beneficial acclimation hypothesis: when is physiological plasticity adaptive? Evolution 56, 1863-1866.

Worland, M.R., 2005. Factors that influence freezing in the sub-Antarctic springtail Tullbergia antarctica. Journal of Insect Physiology 51, 881-894.

Worland, M.R., Leinaas, H.P., Chown, S.L., 2006. Supercooling point frequency distributions in Collembola are affected by moulting. Functional Ecology 20, 323-329.

Young, S.R., Block, W., 1980. Experimental studies on the cold tolerance of Alaskozetes antarcticus. Journal of Insect Physiology 26, 189-200.

Zachariassen, K.E., 1985. Physiology of cold tolerance in insects. Physiological Reviews 65, 799-832. 